\title{
EVALUATION OF MICRO-TPHA, VDRL AND RPR TESTS IN THE SERODIAGNOSIS OF SYPHILIS
}

\author{
T. Santhi ${ }^{1}$, S. Jhansi Lakshmi², G. Lavanya 3 , B. T. V. N. Raju4 ${ }^{4}$ P. Guru Prasad ${ }^{5}$ \\ ${ }^{1}$ Assistant Professor, Department of Dermatology Venereology and Leprosy, Andhra Medical College. \\ ${ }^{2}$ Assistant Professor, Department of Dermatology Venereology and Leprosy, Andhra Medical College. \\ ${ }^{3}$ Post Graduate, Department of Dermatology Venereology and Leprosy, Andhra Medical College. \\ ${ }^{4}$ Assistant Professor, Department of Dermatology Venereology and Leprosy, Andhra Medical College. \\ 5 Associate Professor, Department of Dermatology Venereology and Leprosy, Andhra Medical College.
}

\section{ABSTRACT}

Syphilis is one of the most fascinating diseases of humans. Widespread use of antibiotics now has reduced the incidence of early syphilis and recognized new cases of late syphilis have decreased. Serological tests are the basis for the diagnosis of latent syphilis. They vary in their sensitivity and specificity. While non-treponemal tests (VDRL and RPR) are most frequently used as screening procedures, treponemal tests (FTA-ABS and TPHA) are considered to be highly sensitive and specific.

\section{MATERIALS AND METHODS}

In this study 100 serum samples collected from the patients attending STD Department, King George Hospital, Visakhapatnam. Samples were subjected to VDRL, RPR and Micro-TPHA tests to evaluate the sensitivity and specificity of Micro-TPHA test in patients with various stages of syphilis and to evaluate the efficacy of Micro-TPHA to confirm the diagnosis of syphilis and to rule out biological false positive reactions or false negative reactions of VDRL tests.

\section{RESULTS}

Three tests (VDRL, RPR and Micro-TPHA) were applied to all 100 patients. Among them 85 were VDRL reactive, 84 were RPR positive and 89 were TPHA positive. In them males were more in number, in 3 tests with respect to age, (21-30) age group patients showed predominance. Out of 100 patients, 81 sera were positive for all three tests and one serum sample was VDRL reactive, but RPR and TPHA were non-reactive. This may be a false positive reaction. The following tables showed the sensitivity and specificity of each test and also the sensitivity of each test in various stages of syphilis.

\section{CONCLUSION}

It is concluded as by performing TPHA test, false positive reactivity of VDRL test could be detected. Even in the cases of treated primary and secondary syphilis, TPHA was reactive. The lipoidal antigen tests primarily reflect disease activity and serial quantitative performance of these tests used to measure the treatment response.

\section{KEYWORDS}

Micro-TPHA, VDRL, RPR, Syphilis-Serodiagnosis.

HOW TO CITE THIS ARTICLE: Santhi T, Lakshmi SJ, Lavanya G, et al. Evaluation of Micro-TPHA, VDRL and RPR tests in the serodiagnosis of Syphilis. J. Evolution Med. Dent. Sci. 2016;5(31):1606-1608, DOI: 10.14260/jemds/2016/378

\section{INTRODUCTION}

Treponema pallidum is one of the most common infective agent of genital ulcers, first place being occupied by Human (Alpha) herpes virus infection in the developed countries and by Haemophilus ducreyi in the developing countries. Syphilis is more common in developing countries. ${ }^{1}$ Syphilis appears to be a problem of considerably greater magnitude in countries where health services are relatively poorly developed. Congenital syphilis remains deplorably common. Most specific means of diagnosing Syphilis is demonstration of Treponema pallidum in specimens collected from the lesions by dark field microscopy.2 Serological tests for Syphilis include nontreponemal (Reagin) tests and treponemal tests. ${ }^{3}$

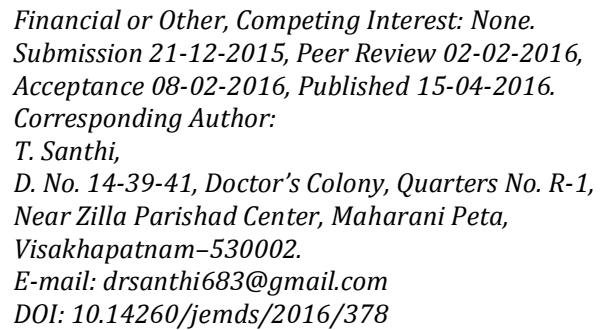

The standard non-treponemal test commonly used in India is the Venereal Disease Research Laboratory (VDRL) slide test for routine serodiagnosis. The Reagin tests are known to give false positive and false negative results. Moreover, the VDRL test may be relatively insensitive in primary and late syphilis. ${ }^{3}$ The Rapid Plasma Reagin (RPR) card test is another simplified non-treponemal test. Currently, four treponemal tests are considered specific tests for syphilis. These include 1. FTA-ABS test, 2. FTA-ABS DS (Double staining), 3. MHA-TP test, 4. HATTS (Haemagglutination Treponemal test for syphilis). These tests have replaced the Treponema Pallidum Immobilization (TPI) test as a routine clinical test procedure and the TPI is limited to a few laboratories, because of the expense involved. 4 At present, FTA-ABS test serves as the standard of sensitivity for the serodiagnosis of syphilis and more specific than VDRL test. ${ }^{2}$ in primary and late syphilis. TPHA test as a simple alternative specific treponemal test suitable for laboratories. ${ }^{5}$

Sensitivity and specificity of TPHA test compared favourably with the TPI and FTA-ABS tests, hence TPHA recommended as a simple alternative specific treponemal test. More so the specificity of micro TPHA test makes it attractive as a screening test. 6 and has proved to be efficient and 
convenient. 7 TPHA test is more sensitive than VDRL and FTAABS test in latent and tertiary stages of syphilis. ${ }^{8}$

\section{MATERIALS AND METHODS}

100 serum samples collected from the patients attending the Department of Sexually Transmitted Diseases, King George Hospital, Visakhapatnam, were subjected to VDRL, RPR and MHA-TP during the period from March 2012 to December 2012. By careful history and through physical examination the grouping of the cases into primary, secondary, latent, late benign and neurosyphilis was done.

\section{COLLECTION OF BLOOD SAMPLES}

Using sterilized syringes and sterile precautions, about $5 \mathrm{cc}$ of blood was withdrawn by venepuncture; 3 cc of blood was collected in dry sterile test tube without adding any anticoagulant and was allowed to clot. After the retraction of clot, specimen was centrifuged. Serum was separated and collected in two sterile bottles. They were stored at $0^{\circ} \mathrm{C}$ in refrigerator and were used for Micro-TPHA test and RPR card test, remaining $3 \mathrm{cc}$ of blood was sent to Microbiology Department for VDRL test.

\section{VDRL SLIDE TEST}

$0.5 \mathrm{~mL}$ of VDRL antigen (Is an alcoholic solution containing cardiolipin, purified lecithin and cholesterol) was added to 4.5 $\mathrm{mL}$ of Buffered saline (Contains formaldehyde, $\mathrm{Na}_{2} \mathrm{HPO}_{4}$, $\mathrm{KH}_{2} \mathrm{PO}_{4}$, Nacl, Distilled water and $\mathrm{pH}$ is 6.0 ) to form $5 \mathrm{~mL}$ of antigen emulsion; $0.05 \mathrm{~mL}$ of heated serum pipetted into VDRL glass slide. One drop of antigen emulsion was added on to the serum, slide was rotated for 4 minutes and examined for clumps formation.

\section{RAPID PLASMA REAGIN TEST}

One drop of $0.05 \mathrm{~mL}$ of unheated serum placed in the circle of the plastic card, after shaking RPR antigen, one drop of this antigen delivered to plastic card and observed for agglutination.

\section{MICRO-TREPONEMA PALLIDUM HAEMAGGLUTINATION TEST}

In this method serum is tested for antibodies which agglutinate tanned sheep erythrocytes, coated with an extract of Nichol's rabbit adapted strain of Treponema pallidum, which is used as an antigen. An absorbing diluent is first used to remove other possibly confusing antibodies from the serum. All positive sera are tested against a control of sheep erythrocytes not coated with T. Pallidum.

\section{OBSERVATIONS AND RESULTS}

Blood samples collected from 100 patients with history and clinical manifestations suggestive of syphilis were subjected to standard tests, VDRL test, RPR and Micro-TPHA tests for evaluation of Micro-TPHA test in comparison with VDRL and RPR tests. Analysis of the results of these tests are given below.

\begin{tabular}{|c|c|c|c|c|}
\hline $\begin{array}{c}\text { Serial } \\
\text { No. }\end{array}$ & Test & Reactive & $\begin{array}{c}\text { Non- } \\
\text { Reactive }\end{array}$ & Total \\
\hline 1. & VDRL & 85 & 15 & 100 \\
\hline 2. & RPR & 84 & 16 & 100 \\
\hline 3. & TPHA & 89 & 11 & 100 \\
\hline
\end{tabular}

\begin{tabular}{|c|c|c|c|c|c|c|c|}
\hline \multirow{2}{*}{ Sex } & \multirow{2}{*}{ Total No. of Cases } & \multicolumn{2}{c|}{ TPHA } & \multicolumn{2}{c|}{ RPR } & \multicolumn{2}{c|}{ VDRL } \\
\cline { 3 - 8 } & & Reactive & Non-Reactive & Reactive & Non-Reactive & Reactive & Non-Reactive \\
\hline Male & 87 & 76 & 11 & 71 & 16 & 72 & 15 \\
\hline Female & 13 & 13 & -- & 13 & -- & 13 & -- \\
\hline Total & 100 & $\mathbf{8 9}$ & $\mathbf{1 1}$ & $\mathbf{8 4}$ & $\mathbf{1 6}$ & $\mathbf{8 5}$ & 15 \\
\hline \multicolumn{7}{|c|}{ TABLE 2: SEX DIFFERENCE IN THE ANALYSIS OF TESTS } \\
\hline
\end{tabular}

\begin{tabular}{|c|c|c|c|c|c|c|c|}
\hline \multirow[b]{2}{*}{ Age } & \multirow[b]{2}{*}{$\begin{array}{c}\text { Total } \\
\text { No. of Cases }\end{array}$} & \multicolumn{2}{|c|}{ VDRL } & \multicolumn{2}{|c|}{ RPR } & \multicolumn{2}{|c|}{ TPHA } \\
\hline & & Reactive & Non-Reactive & Reactive & $\begin{array}{c}\text { Non- } \\
\text { Reactive }\end{array}$ & Reactive & Non- Reactive \\
\hline $11-20$ & 24 & 21 & 3 & 21 & 3 & 22 & 2 \\
\hline $21-30$ & 53 & 43 & 10 & 42 & 11 & 45 & 8 \\
\hline $31-40$ & 17 & 16 & 1 & 16 & 1 & 17 & -- \\
\hline 41 and above & 6 & 5 & 1 & 5 & 1 & 5 & 1 \\
\hline Total & 100 & 85 & 15 & 84 & 16 & 89 & 11 \\
\hline
\end{tabular}

\begin{tabular}{|c|c|c|c|}
\hline \multirow{2}{*}{$\begin{array}{l}\text { No. of } \\
\text { Cases }\end{array}$} & \multicolumn{3}{|c|}{ Results } \\
\hline & TPHA & VDRL & RPR \\
\hline 81 & Reactive & Reactive & Reactive \\
\hline 7 & $\begin{array}{c}\text { Non- } \\
\text { Reactive }\end{array}$ & $\begin{array}{c}\text { Non- } \\
\text { Reactive }\end{array}$ & Non-Reactive \\
\hline 8 & Reactive & $\begin{array}{c}\text { Non- } \\
\text { Reactive }\end{array}$ & Non-Reactive \\
\hline 3 & $\begin{array}{c}\text { Non- } \\
\text { Reactive }\end{array}$ & Reactive & Reactive \\
\hline 1 & $\begin{array}{c}\text { Non- } \\
\text { Reactive }\end{array}$ & Reactive & Non-Reactive \\
\hline 100 & & & \\
\hline & ISOI & DRL ANI & $\begin{array}{l}\text { TEST IN } \\
\text { TESTS } \\
\end{array}$ \\
\hline
\end{tabular}

\begin{tabular}{|c|c|c|c|}
\hline \multirow[b]{2}{*}{ Test } & \multirow{2}{*}{$\begin{array}{l}\text { No. of } \\
\text { Sera }\end{array}$} & \multicolumn{2}{|c|}{ TPHA Test Results } \\
\hline & & Reactive & $\begin{array}{c}\text { Non- } \\
\text { Reactive }\end{array}$ \\
\hline $\begin{array}{c}\text { VDRL } \\
\text { Reactive }\end{array}$ & 85 & 81 & 4 \\
\hline $\begin{array}{l}\text { VDRL Non- } \\
\text { Reactive }\end{array}$ & 15 & 8 & 7 \\
\hline Total & 100 & 89 & 11 \\
\hline
\end{tabular}




\begin{tabular}{|c|c|c|c|}
\hline \multirow{2}{*}{ Test } & \multirow{2}{*}{$\begin{array}{c}\text { No. of } \\
\text { Cases }\end{array}$} & Reactive & Non-Reactive \\
\cline { 3 - 4 } & 84 & 81 & 3 \\
\hline $\begin{array}{c}\text { RPR } \\
\text { Reactive }\end{array}$ & 84 & 8 & 8 \\
\hline $\begin{array}{c}\text { RPR Non- } \\
\text { Reactive }\end{array}$ & 16 & $\mathbf{8 9}$ & $\mathbf{1 1}$ \\
\hline Total & $\mathbf{1 0 0}$ & TI TH Test Result \\
\hline TABLE 6: RESULTS OF MICRO-TPHA IN COMPARISON \\
WITH RPR TEST \\
\hline
\end{tabular}

\section{DISCUSSION}

In the past three decades, technological advances in syphilis serology have been made using more sophisticated equipment and systems. ${ }^{9}$ In the present study, 100 patient's blood samples in different stages of syphilis were subjected to VDRL, RPR and Micro-TPHA tests. Comparison of results of 3 tests showed that out of 100 sera, 85 sera were VDRL reactive and RPR test was in 84 sera. This difference is due to biological false positive serum sample. Out of 100 sera 89 were reactive with Micro-TPHA, but 85 were reactive to VDRL. This difference is due to those 4 samples from treated early syphilis, whereas the treponemal tests (TPHA) tend to remain reactive despite syphilis therapy. $\{$ Table- 2$\}$ showed that out of 100 sera, 87 were males and 13 were females. Since the clinical manifestations of infection were more obvious in men than in women, the usage of available clinical services and reporting of sexually transmitted diseases is more in men. In \{Table- 3$\}$ it had been shown that highest incidence was among the age group of 21-30 years. For most notifiable sexually transmitted diseases, the highest rates of incidence were observed in most sexually active age groups. Comparison of results of three tests is showed in $\{$ Table-4\}. Out of 100 sera, 81 were positive for all three tests. ${ }^{1}$ Sera were positive for both VDRL and RPR tests, but TPHA gave non-reactive result in those 3 patients with complaint of primary chancre of $<1$ month duration. This may be because the TPHA test is relatively insensitive in the early primary stage of syphilis; 8 sera were non-reactive to both VDRL and RPR, but TPHA reactive because those 8 cases were treated cases of early and late syphilis. One serum sample was only VDRL reactive, due to biological false positive reaction. \{Tables-5 \& 6\} showed the comparison between results of TPHA and VDRL tests and TPHA and RPR tests respectively. ${ }^{2}$ They showed the percentage of agreement was about $88 \%$ [Table-5] and 89\% [Table-6] respectively, and the percentage of disagreement was about 12\% [Table-5] and 11\% [Table-6] respectively. 3 This disagreement was due to presence of sera taken from treated early and late syphilitic patients. In such conditions, TPHA appears to be more sensitive.

\section{CONCLUSION}

For screening and diagnostic purposes, two tests, one using the lipoidal antigen [VDRL or RPR] and the other a treponemal antigen [TPHA] are the best choice. Evaluation of standard test revealed sensitivity of RPR and VDRL was in close agreement and specificity of RPR was more than that of VDRL test. Many laboratories do not routinely perform quantitative VDRL tests unless the test is reactive with undiluted serum. ${ }^{10}$ Evaluation of TPHA test in untreated syphilis revealed that during the primary stage of syphilis, TPHA was less sensitive than VDRL and RPR tests. However, in secondary stage the sensitivity of the TPHA test was equal to that of VDRL and RPR tests. But in latent and late stages of the disease, the sensitivity of TPHA was superior to VDRL and RPR tests. By performing TPHA test, false positive reactivity of VDRL test could be detected. As recommended by WHO scientific group, the TPHA test and VDRL or RPR test can be performed in combination for screening as their activity is complimentary. Reagin tests are more sensitive in the detection of early syphilis, whereas TPHA is more sensitive in the detection of latent and late syphilis.

\section{REFERENCES}

1. King PA, Duthic SJ, Ma HK. Sexually transmitted diseases among pregnant vietnamese refugees in Hong Kong. Genitourinary Medicine 1990;66(4):257-8.

2. Jaffe HW. The laboratory diagnosis of syphilis. New concepts. Annals of Internal Medicine 1975;83(6):84650.

3. Laxmi N, Kumar AG. Micro TPHA test in the routine serodiagnosis of syphilis. Indian J of S.T.D. 1990;11(1):911.

4. Garner MF, Blackhouse JL, Daskalopoulos G, et al. Treponema pallidum haemagglutination test for syphilis. Comparison with TPI and FTA-ABS tests. Br J Vene dis 1972;48(6):470-3.

5. Macfarlane DE, Elias Jones TF. Screening tests for syphilis. A comparison of TPHA with two automated serological tests. Br J Vene dis 1977;53(6):348-52.

6. Gavin Hart. Syphilis tests in diagnostic and therapeutic decision making. Ann Intern Med 1986;104(3):368-76.

7. O'Neill P, Warner RW, Nichol CS. TPHA assay in the routine serodiagnosis of treponemal disease. Br J Vene dis 1973;49:427.

8. Leisinske J, Krach J, Kadziewicz E. Specificity, sensitivity and diagnostic value of the TPHA test. Br J Venedes 1974;50(5):334-40.

9. Jhonston NA. Treponema pallidum haemagglutination test for syphilis. Evaluation of micro method. Br J Vene dis 1972;48(6):474-8.

10. Fredrick Sparling. Diagnosis and treatment of syphilis. New England Journal of Medicine 1971;284(12):642-51. 